\title{
Possible mechanisms underlying intermittent synchronous activity in the networks of excitatory and inhibitory bursting neurons
}

\author{
Choongseok Park', Leonid L Rubchinsky ${ }^{1,2^{*}}$ \\ From Twentieth Annual Computational Neuroscience Meeting: CNS*2011 \\ Stockholm, Sweden. 23-28 July 2011
}

Basal ganglia circuits in Parkinson's disease constitute a prominent example of neural system of coupled inhibitory and excitatory neurons, which exhibit synchronous activity [1]. The phase-locking of neural activity in this system, as analyzed in experimental data intraoperatively recorded in Parkinsonian patients, exhibits intermittent temporal dynamics [2]. The mechanisms of this intermittent synchronous dynamics make the subject of this study.

The conductance-based network models of subthalamo-pallidal circuitry of basal ganglia have being shown to reproduce the intermittent temporal patterns of phase-locking observed in experiments with high fidelity [3]. We start with this network model of synaptically coupled excitatory subthalamic and inhibitory pallidal bursting neurons. We further reduce it to the model of two mutually coupled inhibitory neurons with self-inhibition. This network is presented at Figure 1. While real subthalamic neurons are excitatory, the resulting twoneurons network is adequate simplification of the original circuitry under assumption of high fidelity of

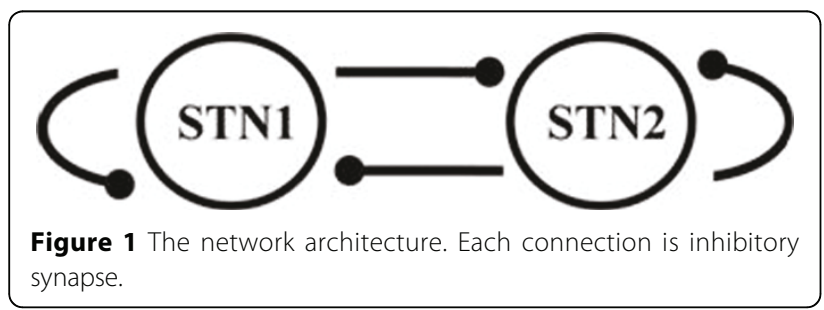

\footnotetext{
* Correspondence: leo@math.iupui.edu

'Department of Mathematical Sciences and Center for Mathematical Biosciences, Indiana University Purdue University Indianapolis, Indianapolis, IN 46202, USA

Full list of author information is available at the end of the article
}

responses of inhibitory pallidal cells. While this reduction may be associated with the loss of some other biologically realistic features, it produces a relatively generic circuit, therefore the studied mechanism may be quite general too.

We used geometric dynamical systems and singular perturbation methods to reduce the full model to a simpler set of equations. Mathematical analysis was completed using three slow variables with two different time scales. Intermittently synchronous oscillations are generated by overlapped spiking which crucially depend on the geometry of slow phase plane and the interplay between slow variables as well as the strength of synapses. Two slow variables are responsible for the generation of out-of-phase stable solution and the other slower variable for irregular and intermittent activity pattern. The results of analysis can be traced to particular values of biophysical parameters (synaptic strength and parameters of calcium dynamics), which are known to be impacted in Parkinson's disease.

\section{Acknowledgements \\ This study was supported by NIH grant R01NS067200 (NSF/NIH CRCNS program).}

\section{Author details}

Department of Mathematical Sciences and Center for Mathematical Biosciences, Indiana University Purdue University Indianapolis, Indianapolis, IN 46202, USA. ${ }^{2}$ Stark Neurosciences Research Institute, Indiana University School of Medicine, Indianapolis, IN 46202, USA.

Published: 18 July 2011

\section{References}

1. Hammond C, Bergman H, Brown P: Pathological synchronization in Parkinson's disease: networks, models and treatments. Trends Neurosci 2007, 30:357-364.
C Biomed Central

(c) 2011 Park and Rubchinsky; licensee BioMed Central Ltd. This is an open access article distributed under the terms of the Creative Commons Attribution License (http://creativecommons.org/licenses/by/2.0), which permits unrestricted use, distribution, and reproduction in any medium, provided the original work is properly cited. 
2. Park C, Worth RM, Rubchinsky LL: Fine temporal structure of beta oscillations synchronization in subthalamic nucleus in Parkinson's disease. J Neurophysiol 2010, 103:2707-2716.

3. Park C, Worth RM, Rubchinsky LL: Neural dynamics in parkinsonian brain: the boundary between synchronized and nonsynchronized dynamics. Phys Rev E 2011.

doi:10.1186/1471-2202-12-S1-P276

Cite this article as: Park and Rubchinsky: Possible mechanisms underlying intermittent synchronous activity in the networks of excitatory and inhibitory bursting neurons. BMC Neuroscience 201112 (Suppl 1):P276.

Submit your next manuscript to BioMed Central and take full advantage of:

- Convenient online submission

- Thorough peer review

- No space constraints or color figure charges

- Immediate publication on acceptance

- Inclusion in PubMed, CAS, Scopus and Google Scholar

- Research which is freely available for redistribution

Submit your manuscript at www.biomedcentral.com/submit
() Biomed Central 